\title{
DEVELOPMENT OF QUICK RETURN MECHANISM FOR EXPERIMENTATION USING SOLIDWORKS
}

\author{
NURUDEEN OLATUNDE ADEKUNLE ${ }^{1}$, KOLAWOLE ADESOLA OLADEJO*2, \\ ISMAILA OLASUNKANMI SALAMI ${ }^{1}$, ADEWALE OREOLUWA ALABI ${ }^{1}$ \\ ${ }^{1}$ Department of Mechanical Engineering, Federal University of Agriculture, Abeokuta, \\ Nigeria \\ ${ }^{2}$ Department of Mechanical Engineering, Obafemi Awolowo University, Ile-Ife, Nigeria
}

\begin{abstract}
Quick Return Mechanisms (QRMs) are one of the essential accessories used in machine tools which involve reciprocating cutting action with a quick return stroke and a constant angular velocity of driving crank. The aim of this work was to simulate, design and construct a prototype of a QRM that can be used for demonstration and instrumentation. The QRM was simulated using Solidworks and a prototype was developed from the simulated results. The experiment was conducted using the prototype. The kinematic simulation of the Solidworks model was compared with the kinematics of motion of the prototype. The result showed that the Percentage Stroke Length error was $0.36 \%$. It was observed that, there was no significant difference in the simulated and experimental results, hence, the prototype can be used for demonstration and experimentation to assist students in understanding basic principles of the machine operation.
\end{abstract}

Keywords: quick return mechanism, solid-work model, prototype, kinematic simulation, stroke length, machine operation

\section{INTRODUCTION}

Assemblage of resistant bodies, connected by movable joints, in order to form a closed kinematic chain with a fixed link for the purpose of motion transmission is known as Mechanism. Such mechanism known as Quick return mechanism are the essential part used in reciprocating cutting tool with a quick return stroke having constant angular velocity of driving crank. Ratio of cutting stroke time to the return stroke is called the time ratio which is greater than one. Confirmed that in QRM, [1] velocity of cutting stroke and return stroke change with change in length of slotter link while the total velocity ratio remained constant [2] calculated the time ratio and stroke length from the given dimension of links with a view of helping designers to design a quick return mechanism for desired stroke length. Forward stroke the velocity of slider reduced gradually to zero by the time the slider was at full stroke [3]. This evidently proved that the elliptical gears wear designed correctly and an alternate mechanism to that of QRM is designed successfully.

This software package is used for rapid prototyping, distance learning and as a teaching aid. Presented an analysis showing the effects of link-length and link-angle tolerances on the shaper-ram stroke error, as well as sensitivity coefficients to link-length and link-angle tolerances $[4,5]$. They observed that the output being most sensitive to the link-length tolerance near the limiting positions of this mechanism was the greatest mechanical error in the

\footnotetext{
* Corresponding author, email: wolesteady@yahoo.com

(c) 2020 Alma Mater Publishing House
} 
output. Developed software using programming language C\# which was useful for synthesis and analysis of crank with sensitive link [6]. It was concluded that the Crank is the most sensitive link.

Finite element analyses of machine parts in static and modal domains are carried out on machine parts and their sub-assemblies [7]. The research resulted in the creation of a dynamic simulation model of the machine structure. Although there is scope for the accuracy of the model to be improved, in its current form it provides a firm basis for predicting the behaviour of the machine. In addition, much can be learned from the simulation model in terms of how the structure is likely to react to different types of excitations. This mechanism was an excellent experience in tackling a design project where the majority of constraints were self-imposed [8]. The final design produced is an effective one; however errors in the model do lead to some doubts as well as areas for the project to progress into. Hopefully, with a little work, the mechanism will be operational and seen by future kinematics students for years to come. Reviews basic QR mechanisms; they presented a project problem and solution examples on drag link quick return mechanism in which the mechanism was simulated using GNLINK and Working Model [9]. From the project problems and solution examples specifically on drag link quick return mechanism, they got results that show the feasible time ratio for varying coupler link, the range of time ratio that would be possible by adjusting the length of the Coupler Link, feasible mechanism solutions that would exist for a given time ratio if both the base length and the coupler link length of the drag link quick return mechanism are changed.

The paper arrangement and testing values of Quick return ratio one when presented on flywheel motor. They were able to present a proposed a Quick return ratio mechanism having ratio one. As well as the tabulated readings of kinetic energy developed for limited period, weight wise and age wise. The data is use for increasing kinetic energy gain and improvement in bicycle which gives the great future in human powered mechanisms [10, 11]. Objective of the project was to investigate the performance of a Crank and lever reciprocating mechanism and to verify that the motion does have a quick return stroke and a slow forward stoke with additionally attaching spraying pump. They determined the increase in efficiency of the system mechanism and also confirmed that the quick return motion may increase the efficiency of the machine $[12,13]$.

The paper also dealt with various literatures in the field of kinematic and dynamic analysis of six-bar quick return mechanism [14, 15]. Static and dynamic force behavior of mechanism was discussed with different types of terminologies and methodologies. They obtained results on how to find the joint forces of different mechanisms using different analytical, graphical, and computer aided programming techniques in which the results can be validated using various motion analysis coordinate systems. The objectives of this study are: (i) Use of SolidWorks to design and analyze a crank and slotted lever mechanism, (ii) Construction of the individual parts of the mechanism according to the results of the design and analysis, (iii) Production of a prototype from the model, and (iv) Comparison between the simulated results and the experimental results.

\section{MATERIAL AND METHODS}

Design Concept: the machine was designed in order to achieve simple technology for an easy operation and fabrication of a motorized device. This device must be capable of simulation design and construct of a prototype of a QRM that can be used for demonstration and instrumentation.

Design data: link AC (link 3) which is the turning pair is fixed (Figure 1), which corresponds to the connecting rod of a reciprocating steam engine. Crank $\mathrm{CB}$ is the driving crank which revolves about the fixed centre $\mathrm{C}$ with uniform angular speed. A sliding block was attached to the crank pin at B slides along the slotted bar AP and make it to oscillate about the pivoting point A. the link PR transmits the motion from AP to the ram which reciprocates the tool along the line of stroke R1R2. The line of the stroke of the ram (R1R2) which is perpendicular to AC produced. When the crank rotates along $\mathrm{CB} 1$ and $\mathrm{CB} 2$ or through an angle $\beta$ in the clockwise direction, the forward stroke occurs, and from CB2 to CB1 gives the return stroke in clockwise direction through angle $\alpha$. The crank has uniform angular speed. The same routine occurs in the extreme position [16,17]

In the extreme positions, AP1 and AP2 are tangential to the circle and the cutting tool is at the end of the stroke. The forward or cutting stroke occurs when the crank rotates from the position CB1 and CB2 (or through an angle $\beta$ ) in the clockwise direction. The return stroke occurs when the crank rotates from the position CB2 to CB1 (or through angle $\alpha$ ) in the clockwise direction. Since the crank has uniform angular speed. 


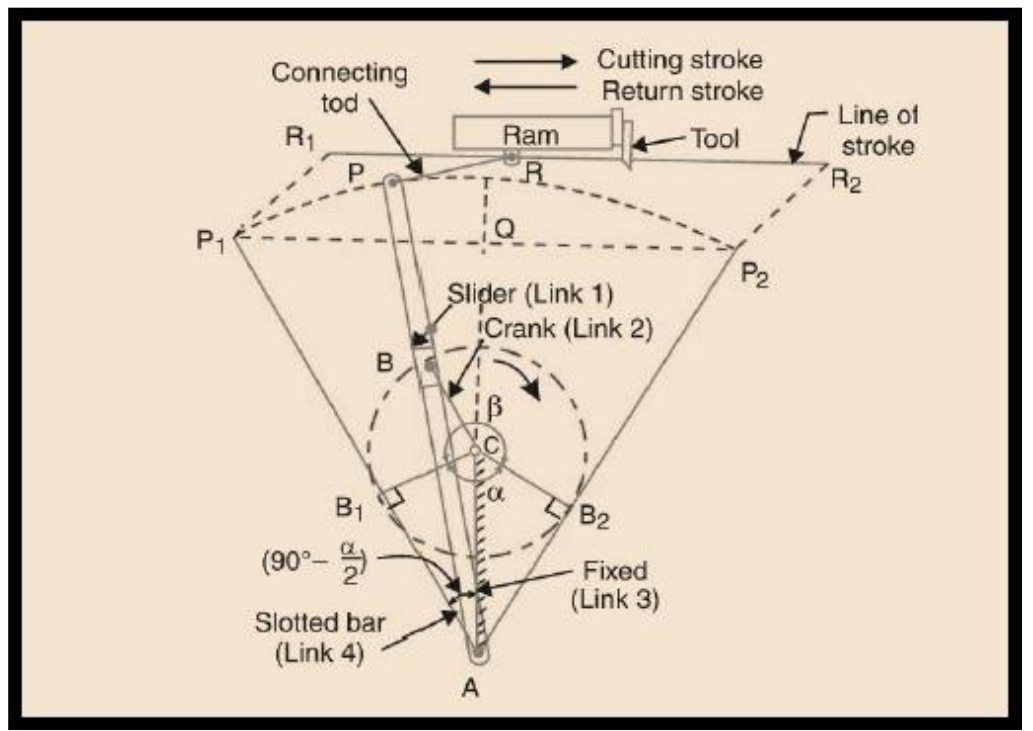

Fig. 1. Crank and Slotted lever Quick Return Mechanism [16].

Therefore,

$$
\frac{\text { Time of Cutting Stroke }}{\text { Time of Return Stroke }}=\frac{\beta}{\alpha}=\frac{\beta}{360^{\circ}-\beta} \text { or } \frac{360^{\circ}-\alpha}{\alpha}
$$

Since the tool travels a distance of R1R2 during cutting and return stroke, therefore travel of the tool or length of stroke:

$$
R 1 R 2=P 1 P 2=2 P 1 Q=2 A P 1 \sin <P 1 A Q=2 A P 1 \sin \left(90-\frac{\alpha}{2}\right)=2 A P \cos \frac{\alpha}{2}=2 A P \times \frac{C B}{A C}
$$

Degree of Freedom: is the number of inputs parameters which predicts a reasonable output.

Using the Gruebler's equations:

$$
M=3 L-2 J-3 G
$$

Quick Return Ration ( $Q R R)$ : is the ratio of the time of cutting stroke to the time of return stroke.

$$
Q R R=\frac{\text { time of cutting stroke or angle of cutting stroke }}{\text { time of return stroke or angle of return stroke }}=\frac{\beta}{\alpha}=\frac{(360-\alpha)}{\alpha}=\frac{\beta}{(360-\beta)}
$$

Crank Radius (r):is one of the two parameters required from the degree of freedom analysis. The quick return mechanism was designed on a 75 .

Length of Slotted Lever (AP):

$$
A P=\frac{P 1 Q}{\sin \left(90^{\circ}-\alpha / 2\right)}
$$

Length from the crank radius and the slotted lever pivot centres $(A C)$ :

$$
A C=\frac{r}{\cos (\alpha / 2)}
$$

Length of Stroke (RIR2):

$$
R I R 2=2 A P \times \frac{r}{A C}
$$


Length of AR:

$$
\begin{gathered}
A Q=A P \cos \left(90^{\circ}-\alpha / 2\right) Q R=P R \sin \left(90^{\circ}-\alpha / 2\right) \\
A R=A Q+Q R \\
\frac{\text { Time of Cutting Stroke }}{\text { Time of Return Stroke }}=\frac{\beta}{\alpha}=\frac{\beta}{360^{\circ}-\beta} \text { or } \frac{360^{\circ}-\alpha}{\alpha}
\end{gathered}
$$

Since the tool travels a distance of R1R2 during cutting and return stroke, therefore travel of the tool or length of stroke

$$
R 1 R 2=P 1 P 2=2 P 1 Q=2 A P 1 \sin \angle P 1 A Q=2 A P 1 \sin \left(90-\frac{\alpha}{2}\right)=2 A P \cos \frac{\alpha}{2}=2 A P \times
$$

Design for Prototype: was constructed for a Quick Return Ration (QRR) of 2.

Therefore,

$$
2=\frac{\beta}{\alpha}=\frac{360-\alpha}{\alpha}
$$

From equation (10):

$$
2 \alpha=360-\alpha \quad \alpha=120^{\circ}
$$

Substitute $\alpha=120^{\circ}$ into equation (10):

$$
\begin{gathered}
2=\frac{\beta}{\alpha} \\
\beta=2 \times 120=240^{\circ}
\end{gathered}
$$

Calculation of Crank Radius ( $r$ ):is one of the two parameters required from the degree of freedom analysis. The quick return mechanism was designed on a 75 .

$$
\text { Length of Slotted Lever, } \mathrm{AP}=\frac{\mathrm{P} 1 \mathrm{Q}}{\sin \left(90^{\circ}-\alpha / 2\right)}=\mathrm{AP}=275
$$

Length from the crank radius and the slotted lever pivot centres, $A C=\frac{r}{\cos (\alpha / 2)}=150$

$$
\begin{gathered}
\text { Length of Stroke, } R 1 R 2=2 A P \times \frac{r}{A C}=R I R 2=275 \\
\text { Length of } \mathrm{AR}=\mathrm{AQ}+\mathrm{QR}
\end{gathered}
$$

But, $\mathrm{AQ}$ is needs to be calculated. Therefore, $A Q=A P \cos \left(90^{\circ}-\alpha / 2\right)=A Q=238.2$

Also, QR needs to be calculated.

$$
Q R=P R \sin \left(90^{\circ}-\alpha / 2\right)
$$

PR is the Length of the coupler Link used in the design $=188 \mathrm{~mm}$ (this dimension can be assumed) $=Q R=$ $188 \sin \left(90^{\circ}-60^{\circ}\right)=94$

$$
\text { Length of } \mathrm{AR}=238.2 \mathrm{~mm}+94 \mathrm{~mm}=332.2
$$

\subsection{Design specifications}

Quick Return Ratio 2, Stroke Length 275, Coupler Link 188, Slotted Lever 275, Crank Radius 75, and Electric 
Motor rating (220V -240V, 30rpm, 0.38mA, shaft diameter $=9$ )

Solidworks Model and Prototype Component Parts: the component parts from the Solidworks model (Figure 2): slotted lever, guide, crank, coupler link, slider, flange and base.

Prototype Component Parts (Figure 3): these components are what make up the frame work for the construction of the prototype: (1) Slotted Lever, (2) Guides, (3) Crank, (4) Coupler Link and Slider, (5) Speed Regulator and Switch, (6) Electric Motor, and (7) Base Box.

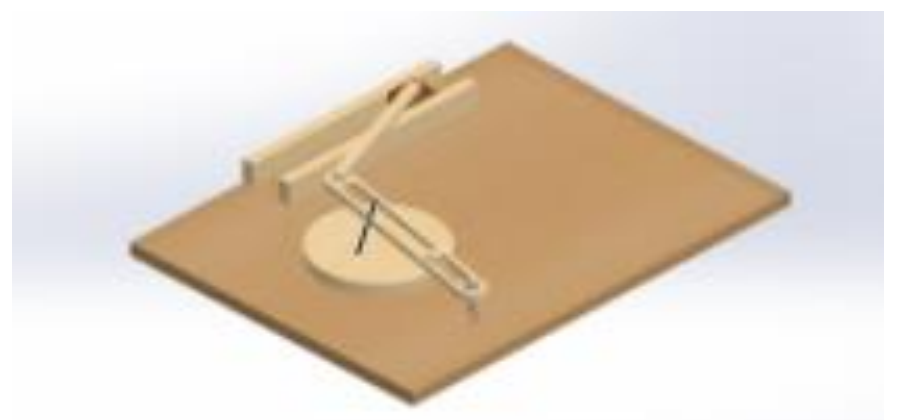

Fig. 2. Modelled Quick Return Mechanism using Solid work.

Materials used for Prototype: wood, Bolt and nut of size 10 were used, Glue, Nails, the electric motor. Screws, Switch, Speed Regulator Ruler: the Guiders, Printable Protractor. Equipment:saw, Hammer, Drilling machine, Planer and Chisel.Various procedures were used in the construction of the prototype, these include: woodwork operations: cutting of the plank with a saw into desired shapes, cutting of the coupler link, slider, crank and guards, cutting of the base and planning of the wooden surfaces. Mechanical workshop operations: drilling of holes with the use of the drilling machine based on the dimensions in the design drawing, making of the flange, fixing of the flange to the crank, and fixing of the electric motor to the base. Electrical operations: connection of the switch and regulator to the electric motor.
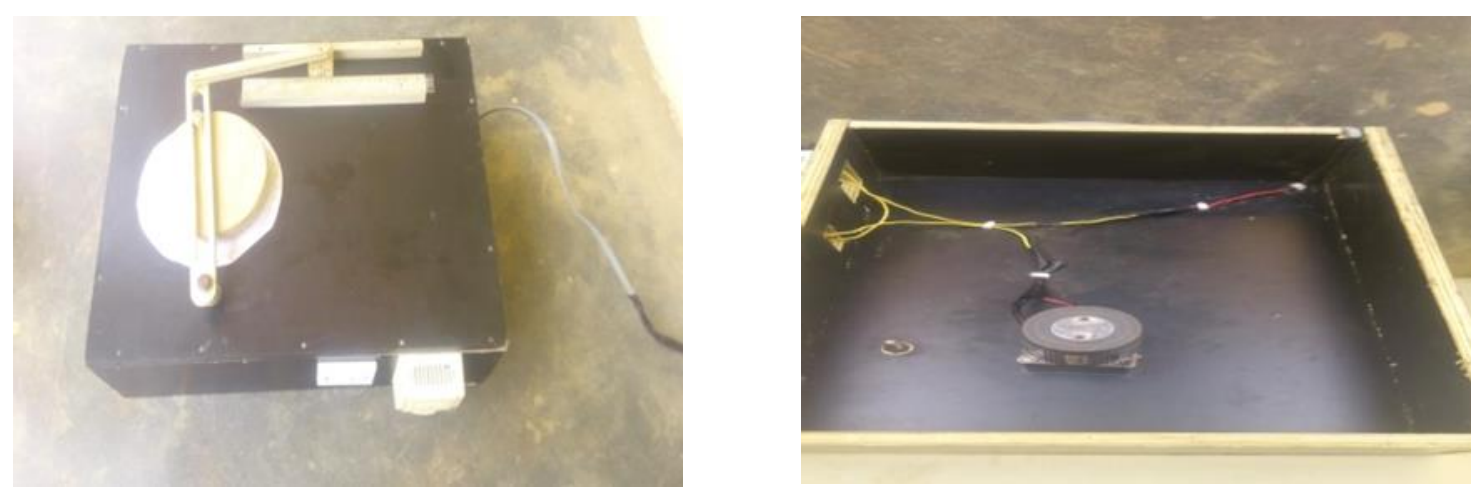

Fig. 3. Prototype Quick Return Mechanism constructed.

\section{Method of Data Collection and Analysis}

The following methods of data collection and analysis were applied during the course of the project:

- Measurements were taken directly from the Prototype, in which the angular displacement of the crank and their corresponding linear displacement values were taken and recorded.

- The SolidWorks model was simulated to get the results. This was done once the assembly of the model was concluded. The simulation showed how the slider will move in real life experience.

\section{RESULTS AND DISCUSION}

The relationship between the slider displacement from the crank center measured in meters and the crank angular displacement measured in degrees are shown in as plotted with the use of EXCEL are shown in Figure 4, significant points have been labeled and explained as Return/forward stroke and Working/Backwards Stroke: 
- Return/Forward Stroke: it can be seen that there was an increase in the positioning of the Slider even as the angular displacement of the crank increase. The Return Stroke started from 0 degrees at $0.001 \mathrm{~m}$ Slider displacement to 120 degrees at $0.275 \mathrm{~m}$ Slider displacement.

- Working/Backwards Stroke: it can be seen that there was a decrease in the positioning of the Slider even as the angular displacement of the crank increase. The Working Stroke started from 120 degrees at $0.275 \mathrm{~m}$ Slider displacement to 360 degrees at $0.001 \mathrm{~m}$ Slider displacement.

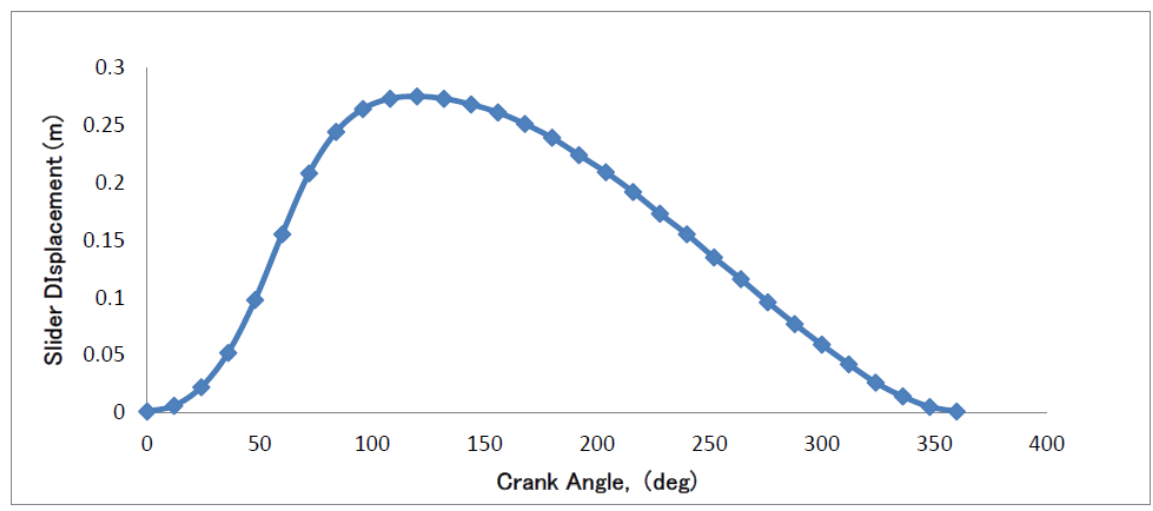

Fig. 4. Slider Displacement against Crank Angle of Solidworks Model.

The relationship between the velocity of the Slider and the time elapsed during the motion simulation performed on the SolidWorks are shown in Figure 5. Significant points have been labeled and explained as:

- 1 - 2: this is referred to as the return/forward stroke and it involves a change in crank angle from 0 degrees to 84 degrees with a corresponding sharp increase in velocity from $0 \mathrm{~m}$ to $0.523 \mathrm{~m} / \mathrm{s}$;

- 2 - 3: this is referred to as the working/backwards stroke and it involves a change in crank angle from 84 degrees to 360 degrees with a corresponding gradual decrease in velocity from $0.523 \mathrm{~m} / \mathrm{s}$ to $0.0005 \mathrm{~m}$.

The slider velocity at point 1 is $0 \mathrm{~m} / \mathrm{s}$ and the slider velocity at point 2 is $0.523 \mathrm{~m} / \mathrm{s}$ while the slider velocity at point 3 is $0.001 \mathrm{~m} / \mathrm{s}$. It is seen that, as against the conventional motion of the crank and slotted lever mechanism which have the forward stoke first with the return stroke following, this crank and slotted lever mechanism has the return stroke first and the forward or cutting stroke following.

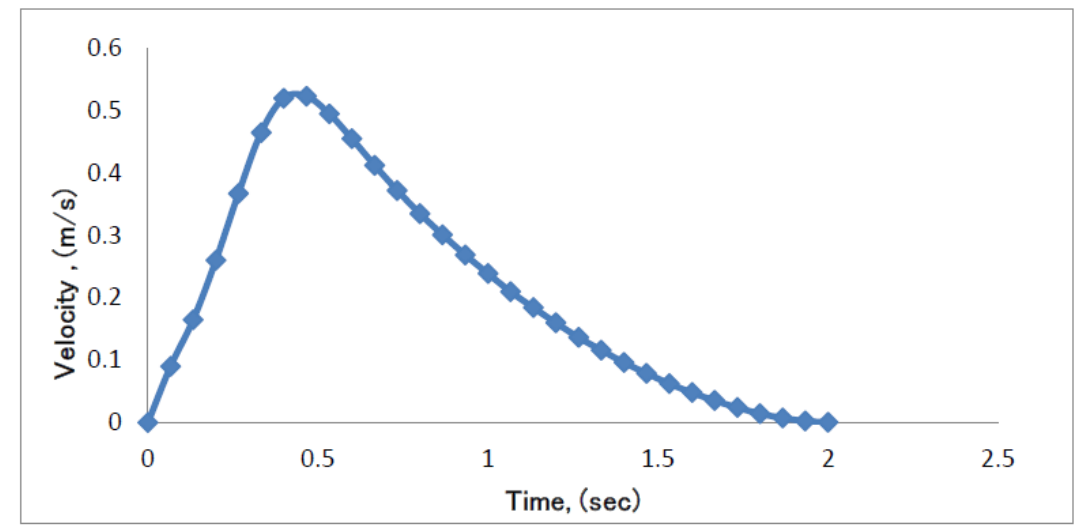

Fig. 5. Velocity Profile of Solidworks Model.

The relationship between the acceleration of the Slider and the time elapsed during the simulation performed on the SolidWorks are shown in Figure 6 below. Significant points have been labeled and explained.The acceleration of the Slider rise rapidly to $1.35 \mathrm{~m} / \mathrm{s}^{2}$ of (2) within 0.067 seconds through an angular displacement of 12 degrees for the crank. After this, there was a slight fall in acceleration for the next 0.13 seconds which is followed by a sinusoidal increase in acceleration of the Slider to a maximum value of $1.395 \mathrm{~m} / \mathrm{s}^{2}$ at 60 degrees. Then, followed by gradual decline in acceleration of the Slider to $0.00025 \mathrm{~m} / \mathrm{s}^{2}$ at 360 degrees. 


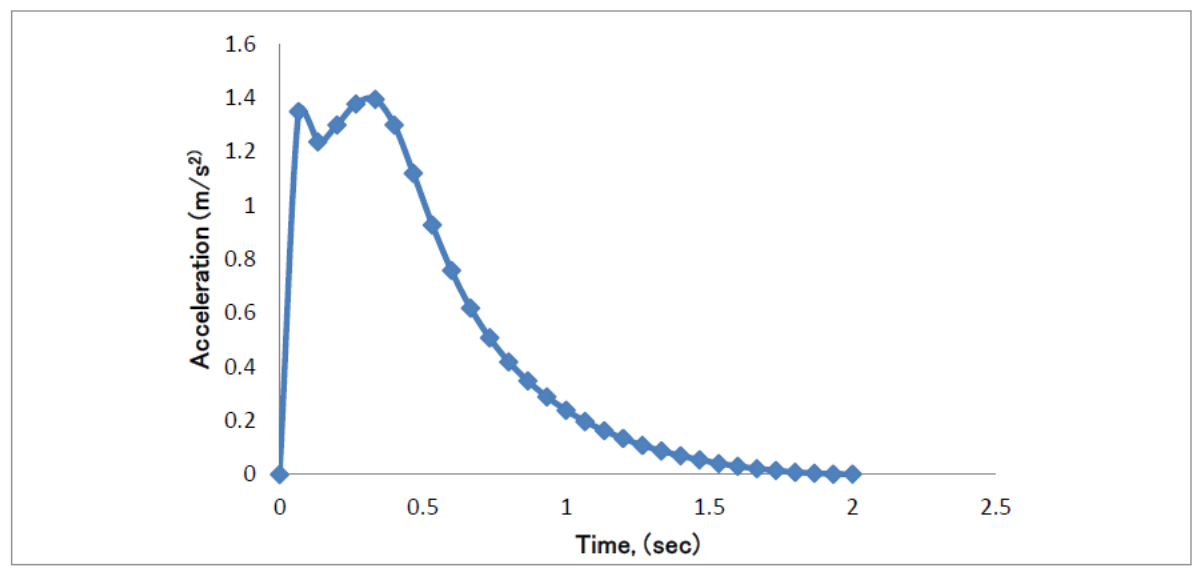

Fig. 6. Acceleration Profile of SolidWorks Model.

\subsection{Results from the Prototype Constructed}

The experimental results obtained from the prototype constructed shows that The Stroke Length (S) for the prototype is given as the difference between the highest slider displacement and the lowest slider displacement, $\mathrm{S}$ $=0.275-0=0.275 \mathrm{~m}$. The forward/return stroke started from the crank angle 0 degrees with corresponding slider displacement of $0.000 \mathrm{~m}$ and ended at the crank angle 120 degrees with corresponding slider displacement of 0.275 $\mathrm{m}$ (TDC). The backward/working stroke started from the crank angle 120 degrees with corresponding slider displacement of $0.275 \mathrm{~m}$ (TDC) and ended at the crank angle 360 degrees with corresponding slider displacement of $0.000 \mathrm{~m}$

The relationship between the slider displacement from the crank center measured in meters and the crank angular displacement measured in degrees are shown as plotted in Figure 7, significant points have been labeled and explained as shown below:

- 1-2:referred to as the return stroke and it involves a change in crank angle from 0 degrees to 120 degrees with a corresponding change in slider displacement from $0 \mathrm{~m}$ to $0.275 \mathrm{~m}$;

- 2-3:referred to as the forward stroke and it involves a change in crank angle from 120 degrees to 360 degrees with a corresponding change in slider displacement from $0.275 \mathrm{~m}$ to $0 \mathrm{~m}$.

The slider displacement at point 1 is $0 \mathrm{~m}$ and the slider displacement at point 2 is $0.275 \mathrm{~m}$ which represents the stroke length of the slider while the slider displacement at point 3 is $0 \mathrm{~m}$ which represents the end of the cutting or forward stroke.

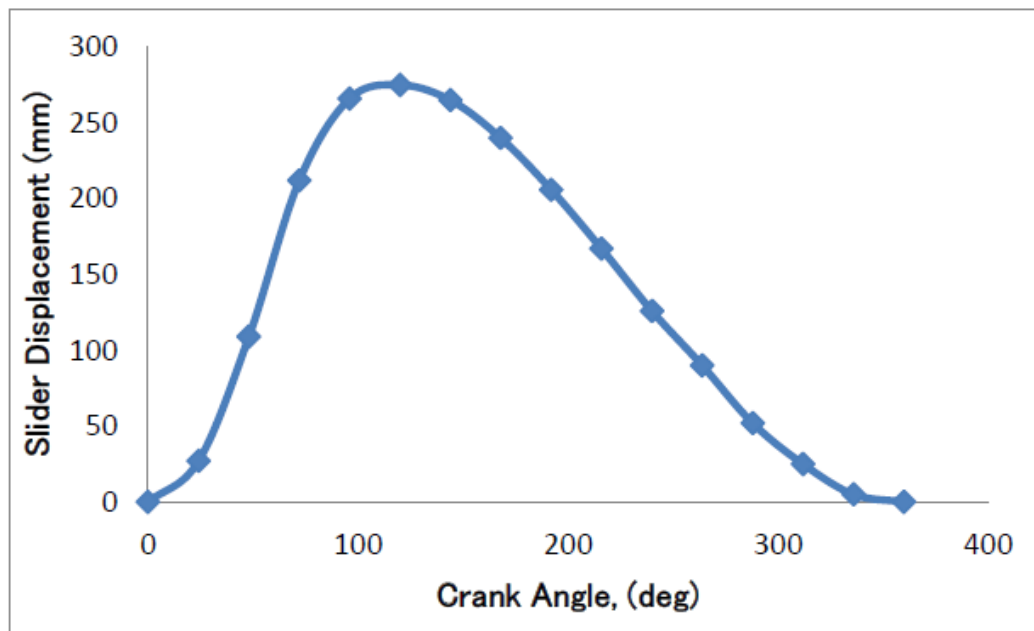

Fig. 7. Graph of Slider Displacement against Crank Angle of Prototype. 


\subsection{Investigation of Kinematics of Motion}

This shows the comparison between the experimental results of the prototype and analytical results of the SolidWorks model from MS EXCEL. The analytical results of the SolidWorks model from MS EXCEL were made the standard by which the comparison was done. $X(\mathrm{~m})=$ Prototype Slider displacement, $\mathrm{x}(\mathrm{m})=$ SolidWorks Slider displacement.The graph in Figure 8 shows the relationship between the measured slider displacement from the prototype and the analytic values of Solidworks obtained from MS EXCEL, it can be seen from the Figure 8 that both curves follow the same sinusoidal path and the maximum and minimum values of both curves coincide at the same angular displacements.

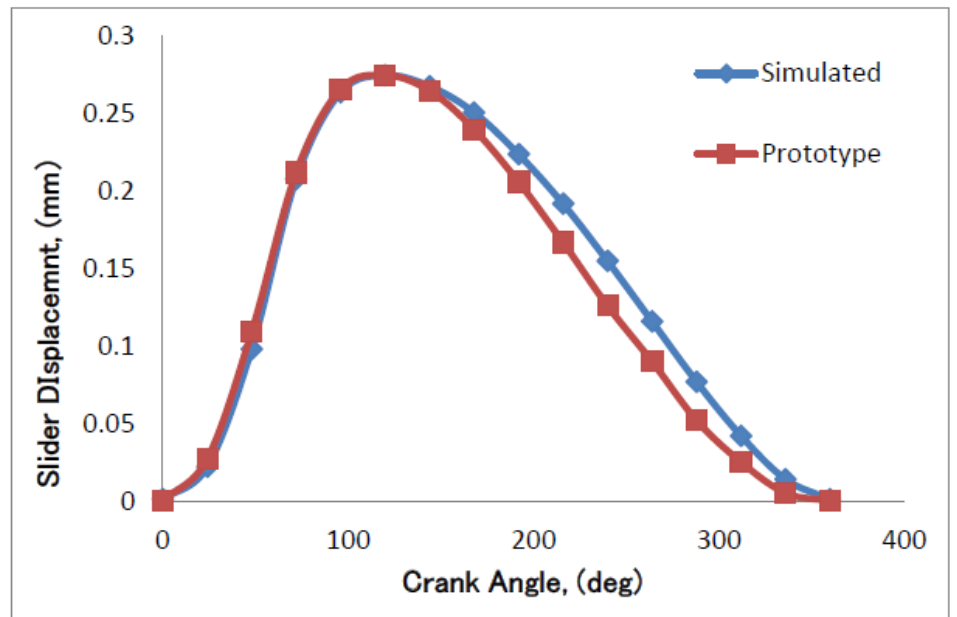

Fig. 8. Analytical Slider Displacement of SolidWorks model and Experimental Slider Displacement Prototype.

\section{CONCLUSIONS}

The following are the deductions and explanations from the results obtained:

- The maximum slider displacement for both SolidWorks model and Prototype was $0.275 \mathrm{~m}$, while the minimum slider displacement for both SolidWorks model and Prototype were at 0.001 and 0.000 respectively.

- The wave front of the Solid works Model (crank angle and slider displacement graph) in Figure 4 gives the same sinusoidal curve.

- The velocity profile and Acceleration profile of the solid works model are shown in Figures 5 and 6.

- It can be seen from the prototype that the maximum slider velocity and maximum slider acceleration were 0.520 $\mathrm{m} / \mathrm{s}$ at 72 degrees and $0.928 \mathrm{~m} / \mathrm{s}^{2}$ at 96 degrees respectively.

- The wave front of the prototype against the solid work model as seen in Figure 8, gives the same and very close curvilinear pattern with a positive correlation of 0.992 .

- The Stroke Length of the Solidworks Model was found to be $0.274 \mathrm{~m}$ which is not equal to the calculated Stroke Length of $0.275 \mathrm{~m}$; this is due to some technicalities within the SolidWorks design model and that the Stroke Length was gotten from the $\mathrm{z}$ plane of the SolidWorks design environment.

- The Percentage Stroke Error $=\frac{\text { Expected value }- \text { Actual Value }}{\text { Expected Value }} \times 100 \%=\frac{0.275-0.274}{0.275} \times 100 \%=0.36 \%$ (percentage error can be ignored because it was very minute).

It could be concluded that similar results were obtained for the Solidworks model and the prototype which confirmed the kinematics of motion of a crank and slotted lever quick return mechanism. The constructed prototype provides a framework for both experimentation and demonstration. The gives a leverage to which international standards can be achieved as regards the availability of Crank and Slotted Lever Quick Return Mechanism in Nigerian Universities.

\section{ACKNOWLEDGEMENTS}

The authors would like to acknowledge Department of Mechanical Engineering, Obafemi Awolowo University, and Department of Mechanical Engineering, Federal University of Agriculture, Abeokuta, Nigeria, for supporting the present work through Research Fund. 


\section{REFERENCES}

[1] Patel, S.R., Patel, D.S., Dynamic analysis of quick return mechanism using MATLAB, International Journal of Engineering Science and Innovative Technology, vol. 2, no. 3, 2013, p. 346-350.

[2] Shelare, S.D., Thakare, P.S., Handa, C.C., Computer aided modelling and position analysis of crank and slotted lever mechanism, International Journal of Mechanical Engineering and Robotics Research,vol. 2, no. 2, 2012 , p. 47-52.

[3] Jasti, S.P., Anil, K.S., Naveen, K.D., Elangovan, M., Design of whitworth quick return mechanism using non circular gear, Proceedings of $8^{\text {th }}$ IRF international conference, Pune, India, vol. 2, no. 6, 2014, p. 59-64.

[4] Pavlović, N.D., Analysis of mechanical error in function generating mechanism, Proceedings of the $11^{\text {th }}$ World Congress on TMM, Tianjin, China, vol. 3, 2004, p. 1240-1244.

[5] Adekunle, N.O., Oladejo, K.A., Ismaila, S.O., Akinduro, O., Development of a prototype demo-slider crank mechanism for demonstration using Solidworks, International Conference of Mechanical Engineering, Energy Technology and Management, IMEETMCON 2018, p. 24 - 31.

[6] Abu, R., Oluwafemi, J. A., Oladejo, K.A., Development of computer-based model for gear design and analysis, International Conference of Mechanical Engineering, Energy Technology and Management, IMEETMCon 2016007, 2016, p. $92-113$.

[7] Nasser, M.A., Asy, M.A., Dynamic, kinematic and static analysis of shaper machine, International Journal of Advanced Engineering and Global Technology, vol. 3, no. 6, 2015, p. 715-725.

[8] Oladejo, K.A., Koya, O.A., Using visio for vector analysis in undergraduate engineering mechanics, Journal of Computer Science and Its Application, vol. 16, no. 1, 2009, p. 23-33.

[9] Podhorodeski, R.P., Nokleby, S.B., Wittchen, J.D., Quick return mechanism design and analysis project, International Journal of Mechanical Engineering Education, vol. 32, no. 2, 2004, p. 273-284.

[10] Padghan, K.K., Warghade, P.S., Astonkar, D.V., Kinetic energy gain in human powered flywheel motor by using quick return mechanism having ratio one, International Journal of Pure and Applied Research in Engineering and Technology, vol. 3, no. 9, 2015, p. 452-460.

[11] Bamiro, O.A., Mechanics and strength of deformable materials, Tertiary Educaation Trust Fund/Ibadan University Press, 2014, p. 489-583.

[12] Avadhut, A.T., Shah, P.T., Shaikh, K., Crank and lever reciprocating mechanism, International Journal for Scientific Research and Development, vol. 3, no. 1, 2015, p. 1418-1419.

[13] Wen-Hsiang, H., Chia-Heng, T., A study on a novel quick return mechanism, Transactions of the Canadian Society for Mechanical Engineering, vol. 33, no. 3, 2009, p. 487-500.

[14] Lokesh, R.A., Dhumne L.R., Aloni, S.N., A review on static and dynamic force behavior of six-bar quick return mechanism, International Journal of Engineering and Innovative Technology, vol. 2, no. 11, 2013, p. 1-3.

[15] Lekurwale, R.A., Mogbe, S.D., Ingle, P.B., Kalaspurkar, K.N., Waghchore, R.K., Kinematic analysis of Sixbar quick return mechanism using complex algebra, International journal of advanced engineering sciences and technologies, no 6, 2011, p. 70-76.

[16] Khurmi, R.S., Gupta, J.K., Machine design, Eurasia Publishing House, New Delhi, 2004.

[17] Rajput, R.K., Strength of materials, Chand S. and Company, New Delhi, 2002. 